\title{
Monolithic Zirconia for Prosthetic Reconstructions: Advantages and Limitations
}

\author{
da Silva, Lucas Hian ; de Lima, Erick ; Hochman, Miriam ; Özcan, Mutlu ; Cesar, Paulo Francisco
}

\begin{abstract}
Purpose of Review Due to frequent clinical reports on chipping of the veneering ceramic applied on zirconia frameworks, non-veneered monolithic zirconia has been proposed in an attempt to improve the lifetime of metal-free fixed dental prostheses (FDPs). This review highlights the effects of microstructure and chemical composition on optical properties and mechanical properties of monolithic zirconia that may be detrimental on the longevity of FDPs and the antagonist dentition. Recent Findings The reviewed studies indicated that the lack of veneering ceramic in monolithic solutions yields to less favourable optical outcome and decreased mechanical stability. Efforts are being made to improve translucency of monolithic zirconia through modifying the grain size, increasing cubic phase, and decreasing alumina content, final density and level of impurities. Summary There appears room for improvement in the microstructure of monolithic zirconia ceramics to achieve better optical results and low antagonist wear, without jeopardizing its mechanical properties.
\end{abstract}

DOI: https://doi.org/10.1007/s40496-017-0153-z

Posted at the Zurich Open Repository and Archive, University of Zurich

ZORA URL: https://doi.org/10.5167/uzh-146727

Journal Article

Accepted Version

Originally published at:

da Silva, Lucas Hian; de Lima, Erick; Hochman, Miriam; Özcan, Mutlu; Cesar, Paulo Francisco (2017). Monolithic Zirconia for Prosthetic Reconstructions: Advantages and Limitations. Current Oral Health Reports, 4(3):197-200. DOI: https://doi.org/10.1007/s40496-017-0153-z 


\section{Monolithic Zirconia for Prosthetic Reconstructions: Advantages and Limitations}

Lucas Hian da Silva ${ }^{1} \bullet$ Erick de Lima ${ }^{2} \bullet$ Miriam Hochman ${ }^{1} \bullet$ Mutlu Özcan ${ }^{3,{ }^{*}} \bullet$ Paulo Francisco Cesar $^{2}$

1University Cidade de São Paulo (UNICID), School of Dentistry, São Paulo, Brazil

${ }^{2}$ Department of Biomaterials and Oral Biology, School of Dentistry, University of São Paulo, São Paulo, Brazil

${ }^{3}$ University of Zurich, Division of Dental Materials, Center for Dental and Oral Medicine, Clinic for Fixed and Removable Prosthodontics and Dental Materials Science, Zurich, Switzerland

M. Özcan*

University of Zurich, Division of Dental Materials, Center for Dental and Oral Medicine, Clinic for Fixed and Removable Prosthodontics and Dental Materials Science, Plattenstrasse 11, CH-8032, Zurich, Switzerland e-mail: mutluozcan@hotmail.com 
Abstract Due to frequent clinical reports on chipping of the veneering ceramic applied on zirconia frameworks, non-veneered monolithic zirconia has been proposed in an attempt to improve the lifetime of metal-free fixed dental prostheses (FDPs). The lack of veneering ceramic in monolithic solutions yields to less favourable optical outcome and decreased mechanical stability. Efforts are being made to improve translucency of monolithic zirconia through modifying the grain size, increasing cubic phase, and decreasing alumina content, final density and level of impurities. This review highlights the effects of microstructure and chemical composition on optical properties and mechanical properties of monolithic zirconia that may be detrimental on the longevity of FDPs and the antagonist dentition. Current knowledge indicates that there is still room for improvement in the microstructure of monolithic zirconia ceramics to achieve better optical results, low antagonist wear, without jeopardizing its mechanical properties.

Keywords Monolithic zirconia $\bullet$ Zirconia $\bullet$ Y-TZP 


\section{Introduction}

Yttria-stabilized tetragonal zirconia polycrystal (Y-TZP; hereafter: zirconia) has been indicated as a reconstruction material in dentistry since 1990's [1]. Initially, the use of zirconia was restricted to the production of frameworks of metal-free fixed dental prosthesis (FDP). However, soon after its implementation in dentistry, numerous studies reported high incidence of clinical chipping of the corresponding veneering ceramic $[2,3]$. Therefore, in order to circumvent veneering ceramic chipping, which was often irreparable and needed replacement of the FDP, other solutions have been proposed $[4,5]$. One of these solutions involved slow cooling of the veneer/zirconia bilayer after the final sintering cycle of the veneering ceramic which is usually the glaze cycle [6]. This procedure was meant to avoid the critical residual thermal stress accumulation within the veneering layer, yielding to ceramic chipping. Despite the promising results obtained in vitro with the proposed solution, chipping problem could not be entirely eliminated clinically. Thus, the overall success of zirconia FDPs seemed only feasible with the complete elimination of the veneering ceramic in that the FDP would be constructed from monolithic (full-contour) zirconia.

Monolithic zirconia became available for clinical use in $2011[7,8]$ with the expectation that chipping of veneering ceramic would be avoided. The early monolithic zirconia materials were optically not satisfactory due to the inherent low translucency of this type of ceramic and therefore, their use was restricted to the posterior region, where the aesthetic demand is not high $[8,9]$. With the advances in material processing and sintering, recently, more translucent monolithic zirconia ceramics became available. Yet, some concerns exist regarding their longevity $[9,10]$. 


\section{Microstructure and optical properties}

The principal differences between conventionally veneered zirconia and that of monolithic ones is the material microstructure and chemical composition. Optical properties of zirconia are typically dictated by the amount of sintering additives in the material composition [11]. Sintering additives, often metal oxides, result in different structural phases, consequently affecting the refractive indices of zirconia and increasing light scattering [12]. When light scattering is intense; the incident light beam is highly diffused, resulting in an opaque material.

The most frequently used additive in zirconia is aluminum oxide, which is responsible for hindering the growth of the zirconia crystalline grains during sintering [13]. The presence of Alumina in the composition is also associated with the increase in the resistance of zirconia to the phenomenon of low temperature degradation (LTD) [14]. A smaller amount of alumina $(0.1$ mass $\%)$ is in fact better distributed in the microstructure of monolithic zirconia, increasing the translucency as opposed to conventional zirconia, which usually contains 0.43 mass $\%$ of alumina [15].

Several other factors could also increase the translucency of polycrystalline ceramic materials such as grain size, higher density and reduced number of impurities, flaws and porosities [11,16-18]. CAD-CAM processing of zirconia ceramics results frequently in final reconstructions with high density with very low levels of impurities, flaws and porosities. However, controlling the size of the crystalline grain is still considered a challenge to material manufacturers [19].

A commonly used technique to increase the translucency of polycrystalline alumina ceramics is to increase the size of the crystalline grain within the material microstructure 
[20]. Ceramics with larger grain size yields to decreased number of granular borders and therefore less light scattering through the material. Unfortunately, such a technique could not be applied for zirconia since the presence of larger grains in this ceramic results in significant decrease in mechanical properties and stability of the tetragonal phase that in turn increases the incidence of LTD phenomenon [21].

More recently, in an attempt to increase the translucency of zirconia, reducing the size of the crystalline grains has been proposed [18]. Such an approach is essentially based on the premise that the crystalline grain should be reduced down to scale at which the influence of the birefringence phenomenon could be attenuated, resulting in a less opaque material [17]. Birefringence occurs due to the presence of high amount of tetragonal crystalline phase (>90\%) in zirconia. In fact, tetragonal crystals have different refractive indices according to their spatial orientation in the microstructure. Thus, such anisotropic behavior causes the light to undergo significant scattering when passing through zirconia. Previous studies have reported that reduction of the crystalline grain size could yield to significant mitigation of the birefringence phenomenon in anisotropic structures with subsequent increase in translucency of the material $[17,18]$.

Unfortunately, to date, no ideal mathematical model exists to study the possible effects of grain size reduction that could eliminate the birefringence of the tetragonal crystals of zirconia. However, it is anticipated that in order to obtain translucency values close to that of feldspathic porcelain, zirconia crystalline grain size should have a mean diameter close to $120 \mathrm{~nm}$ [17]. Currently, it is not possible to obtain zirconia ceramic blocks with such a grain diameter using conventional sintering furnaces. Nevertheless, it could be stated that the reduction in the dimensions of the grains in monolithic zirconia along with 
the reduction of sintering additives in the composition would result in significant improvements in the translucency of the monolithic zirconia [15,22].

One other important aspect is studying the translucency parameter defined as the color difference measured for a certain material in two different scenarios namely, when placed either on a white or a black background [22]. In order to calculate the difference between the two backgrounds, the color parameters of the given material need to be measured based on the light reflected by the specimen when placed on different backgrounds. When a material has high opacity, the colour difference would be very small indicating that the material has high masking ability when placed over dark substrates. On the other hand, a material that shows high color difference when placed on different backgrounds is considered more translucent. Therefore, higher translucency parameter values are usually found for monolithic zirconia in comparison to the conventional ones [15].

In recent monolithic zirconia ceramics, tetragonal and cubic zirconia grains are being coupled within the same microstructure. Such materials could not be referred as Y-TZP due to the significant amount of cubic zirconia (>25\%) in their composition [23,24]. Monolithic reconstructions containing cubic zirconia phase have certainly higher translucency than conventional zirconia since the material contains regions with isotropic refraction index. In fact, less light scattering is anticipated in cubic zirconia, as the refractive index is independent of the crystalline orientation of the grains [24]. Consequently, the birefringence phenomenon associated with the remaining tetragonal grains would be attenuated throughout the material. It is crucial to note that cubic zirconia grains would increase translucency but at the same time they would promote a significant decrease in the mechanical properties of translucent monolithic zirconia compared to 
those of the conventional ones [25]. Although the achieved optical properties for monolithic zirconia could be sufficient for various indications, further improvements are still needed in order to achieve better aesthetics in the anterior region. For this reason, monolithic zirconia FDPs are still being glazed with a low fusing glaze ceramic that contains coloured oxides [8].

\section{Mechanical properties of monolithic zirconia}

Flexural strength, fracture toughness and hardness are some of the parameters used for quantifying the mechanical properties of ceramic materials. Due to its flexural strength being much higher than those of many other ceramic materials, zirconia has been referred as "ceramic steel" [26]. Monolithic zirconia shows higher flexural strength but similar fracture toughness compared to conventional veneered zirconia [27], providing that these results are derived from static loading conditions without involving fatigue parameters (Table 1).

\begin{tabular}{lccc}
\hline \multicolumn{1}{c}{ Material } & $\begin{array}{c}\text { Flexural Strength } \\
(\mathbf{M P a})\end{array}$ & $\begin{array}{c}\text { Fracture } \\
\text { toughness } \\
\left(\mathbf{M P a} \cdot \mathbf{m}^{\mathbf{1 / 2}}\right)\end{array}$ & $\begin{array}{c}\text { Hardness } \\
(\mathbf{G P a})\end{array}$ \\
Zirconia for FDP frameworks & 990 & 3.63 & 12.9 \\
Zirconia for monolithic FDPs & 1.416 & 3.24 & 13.1 \\
\hline
\end{tabular}

Table 1. Main mechanical properties of conventional and monolithic zirconia used for FDPs [27]. *Data obtained from zirconia produced by Tosoh Corporation, Tokyo, Japan. Note that the presented data is only representative and large variations could be observed between different brands of zirconia products available on the dental market. 
Among all mechanical parameters, the hardness value of 13.1 could be considered considerably high compared to those of dental enamel ( 3.2 GPa) or feldspathic ceramic

( $4.5 \mathrm{GPa})$. High hardness values along with other high mechanical properties could potentially wear the antagonist tooth or the restorative material. This becomes more of an issue when veneering ceramic is eliminated in monolithic reconstructions, leaving zirconia in direct contact with the antagonist dentition [28]. Recent research results demonstrated that excellent finishing and polishing of zirconia could significantly reduce antagonist wear $[29,30]$. Yet, monolithic zirconia FDP surfaces and their antagonists should be periodically monitored to ensure the quality of surface finish and potential wear as clinical data are presently limited [31-33].

\section{Concluding remarks}

Since chipping of veneering ceramic could not be completely eliminated with conventional veneered zirconia ceramics, today monolithic zirconia is being considered as an alternative. Yet, optimum translucency remains a drawback and manipulation of translucency may yield to mechanical impairment in the material that needs to be studied in depth prior to their broader clinical indications.

\section{Conflict of Interest}

The authors declare that they have no conflict of interest. 


\section{References}

Papers of particular interest, published recently, have been highlighted as:

- Of importance

•. Of major importance

1. Meyenberg $\mathrm{KH}$, Lüthy $\mathrm{H}$, Schärer $\mathrm{P}$. Zirconia posts: a new all-ceramic concept for nonvital abutment teeth. J Esthet Restor Dent. 1995;7(2):73-80.

2. Swain MV. Unstable cracking (chipping) of veneering porcelain on all-ceramic dental crowns and fixed partial dentures. Acta Biomater. 2009;5(5):1668-77.

3. Tholey MJ, Swain MV, Thiel N. Thermal gradients and residual stresses in veneered Y-TZP frameworks. Dent Mater. 2011;27(11):1102-10.

4. Guazzato M, Walton TR, Franklin W, et al. Influence of thickness and cooling rate on development of spontaneous cracks in porcelain/zirconia structures. Aust Dent $\mathrm{J}$. 2010;55(3):306-10.

5. Rues S, Kroger E, Muller D, et al. Effect of firing protocols on cohesive failure of allceramic crowns. J Dent. 2010;38(12):987-94.

6. Meirelles PD, Spigolon YO, Borba $\mathrm{M}$, et al. Leucite and cooling rate effect on porcelain-zirconia mechanical behavior. Dent Mater. 2016;32(12):e382-e88.

7. Christensen GJ. The all-ceramic restoration dilemma: where are we? J Am Dent Assoc. 2011;142(6):668-71.

8. Marchack BW, Sato S, Marchack CB, et al. Complete and partial contour zirconia designs for crowns and fixed dental prostheses: a clinical report. J Prosthet Dent. 2011;106(3):145-52. 
9. Rinke S, Fischer C. Range of indications for translucent zirconia modifications: clinical and technical aspects. Quintessence Int. 2013;44(8):557-66.

10. Holt LR, Boksman L. Monolithic zirconia: minimizing adjustments. Dent Today. 2012;31(12):78, 80-1.

11. Zhang H, Li Z, Kim B-N, et al. Effect of alumina dopant on transparency of tetragonal zirconia. J Nanomat. 2012;2012:5.

12. Heffernan MJ, Aquilino SA, Diaz-Arnold AM, et al. Relative translucency of six allceramic systems. Part I: Core materials. J Prosthet Dent. 2002;88(1):4-9.

13. Srdić VV, Winterer M, Hahn H. Sintering behavior of nanocrystalline zirconia doped with alumina prepared by chemical vapor synthesis. J Am Ceramic Soc. 2000;83(8):1853-60.

14. Chevalier J. What future for zirconia as a biomaterial? Biomaterials. 2006;27(4):53543.

15. Fathy SM, El-Fallal AA, El-Negoly SA, et al. Translucency of monolithic and core zirconia after hydrothermal aging. Acta Biomater Odont Scand. 2015;1(2-4):86-92.

16. Casolco SR, Xu J, Garay JE. Transparent/translucent polycrystalline nanostructured yttria stabilized zirconia with varying colors. Scripta Materialia. 2008;58(6):516-19.

17. Klimke J, Trunec M, Krell A. Transparent tetragonal yttria-stabilized zirconia ceramics: influence of scattering caused by birefringence. J Am Ceram Soc. 2011;94(6):1850-58.

18. ${ }^{* *}$ Zhang Y. Making yttria-stabilized tetragonal zirconia translucent. Dent Mater. 2014;30(10):1195-203. This review provides all possible methods to developing tetragonal yttria-stabilized zirconia with improved translucency, highlighting the 
birefringence phenomenon of tetragonal zirconia as one of the mechanisms to improve translucency.

19. Jiang L, Liao $Y$, Wan $Q$, et al. Effects of sintering temperature and particle size on the translucency of zirconium dioxide dental ceramic. J Mater Sci: Mater in Med. 2011;22(11):2429-35.

20. Cheng J, Agrawal D, Zhang $Y$, et al. Microwave sintering of transparent alumina. Mater Lett. 2002;56(4):587-92.

21. Papanagiotou HP, Morgano SM, Giordano RA, et al. In vitro evaluation of lowtemperature aging effects and finishing procedures on the flexural strength and structural stability of Y-TZP dental ceramics. J Prosthet Dent. 2006;96(3):154-64.

22. Matsuzaki F, Sekine H, Honma S, et al. Translucency and flexural strength of monolithic translucent zirconia and porcelain-layered zirconia. Dent Mater $\mathrm{J}$. 2015;34(6):910-7.

23. *Anselmi-Tamburini U, Woolman JN, Munir ZA. Transparent nanometric cubic and tetragonal zirconia obtained by high-pressure pulsed electric current sintering. Adv Functional Mater. 2007;17(16):3267-73. This study describes a sintering process to obtain traslucent zironia where grain size and its relation to transluceny is eloborated.

24. *Denry I, Kelly J. Emerging ceramic-based materials for dentistry. J Dent Res. 2014;93(12):1235-42. This review gives an overview on emerging ceramics with an emphasis on specific challenges associated with monolithic zirconia ceramics. 
25. Chevalier J, Deville S, Münch E, et al. Critical effect of cubic phase on aging in 3 mol\% yttria-stabilized zirconia ceramics for hip replacement prosthesis. Biomaterials. 2004;25(24):5539-45.

26. ${ }^{* *}$ Garvie RC, Hannink RH, Pascoe RT. Ceramic steel? Nature. 1975;258(5537):703-

04. This is a classical article describing the importance of phase transformation and its effects on mechanical properties of zirconia.

27. Tong H, Tanaka CB, Kaizer MR, et al. Characterization of three commercial Y-TZP ceramics produced for their high-translucency, high-strength and high-surface area. Ceram Int. 2016;42(1 Pt B):1077-85.

28. Seghi RR, Rosenstiel SF, Bauer P. Abrasion of human enamel by different dental ceramics in vitro. J Dent Res. 1991;70(3):221-5.

29. Preis V, Behr M, Handel G, et al. Wear performance of dental ceramics after grinding and polishing treatments. J Mech Behavior Biomed Mater. 2012;10:13-22.

30. Al-Haj Husain N, Camilleri J, Özcan M. Effect of polishing instruments and polishing regimens on surface topography and phase transformation of monolithic zirconia: An evaluation with XPS and XRD analysis. J Mech Behav Biomed Mater. 2016;64:104-12.

31. Sadid-Zadeh R, Liu PR, Aponte-Wesson R, et al. Maxillary cement retained implant supported monolithic zirconia prosthesis in a full mouth rehabilitation: a clinical report. $\mathrm{J}$ Adv Prosthodont. 2013;5(2):209-17.

32. Limmer B, Sanders AE, Reside G, et al. Complications and patient-centered outcomes with an implant-supported monolithic zirconia fixed dental prosthesis: 1 year results. J Prosthodont. 2014;23(4):267-75. 
33. Moscovitch M. Consecutive case series of monolithic and minimally veneered zirconia restorations on teeth and implants: up to 68 months. Int $\mathrm{J}$ Periodontics Restorative Dent. 2015;35(3):315-23. 